\title{
The Clinical Burden and Spectrum of Ophthalmic Disorders in Stone Industry Employees from Nigeria
}

\author{
Chinyelu Nkemdilim Ezisi', Boniface Ikenna Eze², Obiekwe Okoye², Ada Aghaji², \\ Nkechi Judith Uche ${ }^{2}$, Chimdia Ogbonnaya1, Felix Udenna Ezepue ${ }^{2}$, Rich Umeh ${ }^{2}$ \\ ${ }^{1}$ Federal Teaching Hospital, Abakailiki, Nigeria \\ ${ }^{2}$ Department of Ophthalmology, University of Nigeria Teaching Hospital, Enugu, Nigeria \\ Email: eagleobi@yahoo.com,obiekwe.okoye@unn.edu.ng
}

How to cite this paper: Ezisi, C.N., Eze, B.I., Okoye, O., Aghaji, A., Uche, N.J., Ogbonnaya, C., Ezepue, F.U. and Umeh R. (2018) The Clinical Burden and Spectrum of Ophthalmic Disorders in Stone Industry Employees from Nigeria. Open Journal of Ophthalmology, 8, 191-206.

https://doi.org/10.4236/ojoph.2018.84023

Received: July 3, 2018

Accepted: September 26, 2018

Published: September 29, 2018

Copyright $\odot 2018$ by authors and Scientific Research Publishing Inc. This work is licensed under the Creative Commons Attribution International License (CC BY 4.0).

http://creativecommons.org/licenses/by/4.0/

cc) (i) Open Access

\begin{abstract}
Background: Workers in the stone industry are exposed to many ocular health hazards. There is a paucity of data on the profile of ophthalmic disorders in this vulnerable group, especially in developing countries. Aim: We aimed to determine the burden and spectrum of ophthalmic disorders in stone workers in Abakiliki, Nigeria. Methods: In a population-based cross-sectional survey of stone industry workers conducted in Nigeria, between February and April 2012, relevant data from participants were collected. Descriptive and comparative statistics were performed and statistical significance was indicated by $\mathrm{p}<0.05$ in all comparisons. Results: Participants ( $\mathrm{n}=384$; males, 158 ; females, 226) were aged $32 \pm 11.8$ SD years (range, $14-68$ years) and comprised 105 (27.3\%) stone quarry workers and 226 (72.7\%) stone processing workers. Of these, 298 (77.6\%) had some form of ophthalmic disorder, which frequently involved the ocular anterior segment (69.9\%) or posterior segment (4.9\%). Work-related eye injuries were reported by $36.5 \%$ of employees. Leading disorders were anterior segment: pterygium-associated (37.9\%). Visual impairment (2.9\%) and monocular blindness (1.3\%) were reported. The prevalence of eye disorders was not significantly associated with participant socio-demographic or work characteristics. Male gender $(p=0.001)$ and engagement in stone processing $(p=0.001)$ were significant predictors of work-related eye injury. Conclusions: Among stone industry workers in Abakaliki, Nigeria, there is a high prevalence of ophthalmic disorders, frequently of the ocular anterior segment, and work-related eye injuries are commonly reported. Occupational eye health education, provision of protective eye devices and appropriate ophthalmic care are suggested.
\end{abstract}




\section{Keywords}

Industry, Vision Disorders, Occupational Health Services, Administration, Ophthalmic, Nigeria

\section{Introduction}

Quarrying is the business, occupation, or act of extracting useful materials (such as building stones) from quarries [1]. It is associated with one of the greatest hazard exposures amongst industrial workers [2] [3]. These hazards can cause eye injury-related damage, initiate pathologic processes, or aggravate pre-existing disease conditions or disorders of the eyes [4] [5]. In Nigeria and other parts of Africa, several studies have shown a high incidence of work-related ocular injuries [6] [7] [8]. In Enugu, Nigeria, a prevalence of $81.7 \%$ of eye disorders has been reported, and $28.5 \%$ prevalence in work-related eye injuries among industrial workers has also been reported, apparently resulting from low utilization of protective eye devices while at work [6]. In other related Nigerian surveys, the reported prevalence of work-associated eye injuries ranges from $24.6 \%$ [9] to $52.2 \%$ [10] among welders in Port-Harcourt, Nigeria. Flying objects or particulate matter, hot gases, radiation, and chemical injuries have been implicated as causes of eye injuries at work [6] [9] [10].

Non-traumatic ocular disorders are also common among industrial workers [11] although they could be partly attributed to a trend evident in the general population [6]. Among industry workers, disorders frequently result from induced or aggravated ocular degenerative changes [6] or allergic reactions [4] [12] associated with work-related eye exposures. Work-related injuries can lead to vision loss [13], ocular morbidities, or even loss of the eyeball; these impact adversely on work productivity. Despite the established protective efficacy of personal or machine-based protective eye devices [14] and the explicit provisions of the "General Duty Clause" of the Occupational Safety and Health Act (OSHA) of 1970 [15], industrial eye injuries and morbidities continue to occur, especially in the hazard-prone construction industries. This has been attributed to employers' non-observance of safety rules and employees' non-adherence to the provisions of OSHA and The Factory Act of 1990 [16]. Despite the enormity and visual consequences of job-associated eye injuries and morbidities in this vulnerable group of industrial workers, the ocular health status of such employees remains an under-researched area, especially in low- and middle-income-counties (LMICs) in sub-Saharan Africa [6]. Consequently, between February and March 2012, we conducted a population-based cross-sectional survey to assess the ocular health status of stone quarry workers in Abakaliki town, Ebonyi state, south-eastern Nigeria. The findings generate benchmark data for intra- and inter-country comparisons. Additionally, the data provide an evidence base to assist industrial health policy-makers, planners, implementers 
of industrial health programs, and providers of industrial eye care services in optimizing the ocular health of this particularly susceptible population.

\section{Methods Background}

Ebonyi state has several stone quarries that have been in existence for more than two decades. Although there is a degree of automation in several of the quarries, the majority of workers in state-owned stone quarry industries rely on use of the most primitive implements for surface excavation of stone. To date, there is no industrial health program, catering for the health needs of these workers, nor is there a health policy to ensure adequate protection against work-associated health hazards. This was a population-based, cross-sectional ophthalmic survey of stone quarry and stone processing industry workers in Ebonyi state, which was conducted between February and April 2012.

Eligibility: Technical workers (defined as stone drillers, breakers, and crushers) and labourers who had worked uninterrupted in the stone industry for at least 1 year were eligible. Excluded from participation were ancillary workers i.e. administrative staff and non-technical workers such as drivers and security men.

Ethics: Prior to commencement of the study, ethics clearance, compliant with the 1964 Helsinki Declaration (as amended in 2013) was obtained from UNTH's Medical and Health Research Ethics Committee (Institutional Review Board). Furthermore, study approval was obtained from each stone mining or processing facility whose workers participated in the study. Written informed consent was obtained from each respondent.

Sample size and sampling: Due to a dearth of data from previous reports, we used a 50\% prevalence estimate for eye injuries among stone industry workers and an error band of 5\%. A minimum sample size of 384 was calculated using the formula,

$$
n=\left[z^{2}(1-P) P\right] / d^{2}
$$

where $n=$ minimum sample size; $z=$ standard normal deviation of 1.96 at confidence level of $95 \%, P=50 \%$; $d$ is the desired precision (error band) due to random sampling error of $5 \%=0.05 ; n=\{[1.96 \times 1.96(1-0.5) 0.5] / 0.05\}^{2}=384$.

Sampling technique: The stratified sampling technique was used with a two-stage stratification based on job specification. The first sub-stratification delineated workers in the quarry and in the processing sub-sectors. This was followed by further sub-stratification of each sub-sector, based on job specification i.e. workers in the quarry sector were sub-stratified into blasters, drillers, breakers, and laborers, while workers in the processing sector were sub-stratified into crushers, breakers, and laborers. Each sub-classification based on job specification was adequately sampled. The calculated sample size was distributed amongst the various job specifications, based on proportionate representation. For example, the number (proportionate sample) of drill operators/drillers selected for participation was determined by dividing the total number of drillers by total number of workers, and multiplying this by the calculated sample size 
i.e. [Number of Drillers/Total Number of workers] $\times$ Calculated sample size. After the proportionate sample size was determined for each job specification, the required sample size was drawn from the respective population of each job specification by simple random sampling using the workers' register as the sampling frame. The sampling interval (skip interval, $\kappa$ ) was defined by $n / N$ where $n$ = proportionate sample size and $N=$ total number of workers in each job stratum. After a random start, each $\kappa^{\text {th }}$ name in the trade register was selected until the calculated sample size was obtained.

At the central Quarry site mine; there are 50 companies that operate with a total workforce of approximately 2600 employees. Using probability proportionate to size, the number of workers selected from each job specification was calculated as follows: Blasters: [100/2600] $\times 384=14.76(\sim 15)$; Drillers: [250/2600] $\times 384=36.92(\sim 37)$; Breakers: [100/2600] $\times 384=14.76(\sim 15)$; Laborers: [500/2600] $\times 384=73.84(\sim 74)$. At the Stone processing plant, Crushers: [50/2600] $\times 384=7.38(\sim 7)$; Breakers: [50/2600] $\times 384=7.38(\sim 7)$ and laborers: [1550/2600] $\times 384=228.92(\sim 229)$.

Study instrumentation: The study instrument was a researcher-administered open-ended questionnaire and a proforma designed de-novo by the authors (See Appendix I). Prior to final deployment for the study, and to ascertain its psychometric reliability and construct validity, the instrument was pretested on 140 workers at the Ezza Inyimagu mines in Ebonyi state. The participants in the pretest were excluded from participation in the final survey. Feedback from the pretest informed questionnaire modifications to enhance its appearance, flow, and interpretation. The final version of the questionnaire/proforma contained sub-sections on participants' socio-demographics and work information: this included job description, history of work-related eye injury, adherence to safety measures, and findings on comprehensive ophthalmic examinations. The questionnaire was administered in the English language. However, a native interpreter literate in English, translated the proforma into the respondent's local Igbo dialect, if required.

Study procedure: Questionnaire administration and ophthalmic examinations were performed on each participant at the work site. After the completion of the questionnaire, each participant's monocular distance visual acuity (DVA) was measured using the Snellens' alphabet or illiterate E chart (Unique Opticals, Lagos, Nigeria), at 6 meters. For any DVA measurement less than $6 / 6$, the test was repeated with a pinhole. Binocular near visual acuity (NVA) was measured at a distance of $33 \mathrm{~cm}$ using the Jaeger reading chart (Unique Opticals, Lagos, Nigeria). Both DVA and NVA measurements utilized daylight illumination. The ocular anterior segment was examined using the ophthalmic torchlight loupe (Welch Allyn Inc., Skaneateles Falls, New York, USA) at $\times 4$ magnification and a portable slit lamp bio-microscope (ScanOptics, Adelaide, Australia). Where necessary, suspicious corneal lesions were stained with $2 \%$ sodium fluorescein (Akorn Direct Inc., Illinois, USA) and the slit lamp examination repeated using the cobalt blue interference filter. After achieving satisfactory mydriasis with 
topical tropicamide (Ashford laboratories, Macau, China), posterior ocular segment examination was performed using a direct ophthalmoscope (Welch Allyn Inc, Skaneateles Falls, New York, USA). The intraocular pressure was measured using the hand-held Perkins tonometer (Keeler Instruments, London, UK). Participants with minor eye ailments were treated in the field while those requiring further investigations or definitive treatment were referred to the nearby Ebonyi State University Teaching Hospital (EBSUTH), Abakiliki, Nigeria.

Operational definitions: For the purpose of this study, an industrial accident or injury was defined as any accident occurring during the course of activity related to industrial work [17]. When the eyes were involved, accidents were referred to as industrial eye accidents. Trauma was defined as a cause of blindness or visual impairment if, in the affected eye, it was the last event preceding visual loss [18].

Data analysis: Data were entered into and analyzed using the Statistical Package for Social Sciences (SPSS) software, version 20 (SPSS Inc., Chicago, Illinois, USA). Descriptive statistical analysis yielded frequencies, percentages, and proportions. Inter-group comparisons to test for the significance of observed differences utilized the chi-square test or Fisher's exact test, or categorical variables and student t-test for continuous variables. In all comparisons, statistical significance was indicated by $\mathrm{p}<0.05$.

\section{Results}

Participants' socio-demographic and job characteristics: The participants $(n=384)$ comprised 158 males and 226 females who were aged $32 \pm 11.8 \mathrm{SD}$ years, with an age range of 14 - 68 years. Of these, $26(6.8 \%)$ possessed formal education while $268(69.8 \%)$ were married. The distribution by work sector showed that $105(27.3 \%)$ worked in the quarry while $279(72.7 \%)$ worked in the processing sections of the stone industry. Overall, their cadre distribution was divided as follows: laborers $(75.8 \%)$, blasters $(4.7 \%)$, breakers $(5.7 \%)$, crushers $(12.0 \%)$, and drillers (1.8\%). The socio-demographic and job characteristics are shown in Table 1.

Spectrum of ophthalmic disorders: Ophthalmic disorders were present in 298 (77.6\%) workers and comprised 512 cumulative types of disorders that more frequently involved the ocular anterior segment. 358 (69.9\%) disorders were observed in the whole globe, while 129 (25.2\%) had ocular posterior segment abnormalities and 25 (4.9\%) were comparatively infrequent.

Overall, the leading ophthalmic disorders were those that affected the pterygium $(37.9 \%)$, refractive error (19.5\%), conjunctivitis (13.7\%), and pingueculum (7.6\%) (Table 2 ). The prevalence of eye disorders did not differ significantly by participant age $(\leq 40$ vs. $>40$ years, $p=0.06)$, gender $(p=0.55)$, work experience ( $\leq 10$ vs. $>10$ years, $p=0.98$ ), or work sector (quarry vs. processing, $p=0.63$ ).

Work-related eye injuries: Of the 246 (64.1\%) workers with a previous history of work-related eye injury, the commonest types of injuries reported were 
Table 1. Participants' socio-demographics and work characteristics.

\begin{tabular}{|c|c|}
\hline Characteristics & $n(\%), N=384$ \\
\hline \multicolumn{2}{|l|}{ Age (years) } \\
\hline $10-20$ & $29(7.6)$ \\
\hline $21-30$ & $122(31.8)$ \\
\hline $31-40$ & $122(31.8)$ \\
\hline $41-50$ & $84(21.9)$ \\
\hline $51-60$ & $22(5.7)$ \\
\hline $61-70$ & $5(1.3)$ \\
\hline \multicolumn{2}{|l|}{ Gender } \\
\hline Male & $158(41.1)$ \\
\hline Female & $226(58.9)$ \\
\hline \multicolumn{2}{|l|}{ Educational status } \\
\hline None & $146(38.0)$ \\
\hline Primary & $115(29.9)$ \\
\hline secondary & $97(25.3)$ \\
\hline Tertiary & $26(6.8)$ \\
\hline \multicolumn{2}{|l|}{ Work Sector } \\
\hline Stone quarry & $105(27.3)$ \\
\hline Stone processing & $279(72.7)$ \\
\hline
\end{tabular}

Table 2. Spectrum of 512 eye disorders/diseases observed among 384 participants.

\begin{tabular}{|c|c|}
\hline Types of eye disorders/disease & $n(\%), N=512$ \\
\hline \multicolumn{2}{|l|}{ Anterior segment } \\
\hline Pterygium & $194(37.9)$ \\
\hline Conjunctivitis & $70(13.7)$ \\
\hline Pingueculum & $39(7.6)$ \\
\hline Cataract & $33(6.5)$ \\
\hline Others & $22(4.3)$ \\
\hline \multicolumn{2}{|l|}{ Posterior segment } \\
\hline Glaucoma & $11(2.1)$ \\
\hline Optic atrophy & $8(1.6)$ \\
\hline Others & $6(1.2)$ \\
\hline \multicolumn{2}{|l|}{ Whole globe } \\
\hline Refractive error & $100(19.5)$ \\
\hline Presbyopia & $24(4.7)$ \\
\hline Others & $5(0.9)$ \\
\hline
\end{tabular}


superficial ocular foreign body (69.1\%), blunt trauma (24.0\%), superficial ocular abrasion (4.9\%), burns (1.2\%), allergic peri-ocular skin peeling (0.4\%), and penetrating injury $(0.4 \%)$. Injury caused severe monocular visual impairment (DVA of $<6 / 60-3 / 60)$ in $2(0.8 \%)$ workers. Work-associated eye injuries were more frequently observed among processing workers compared with quarry workers (Table 3$)$. Male gender $(\mathrm{p}=0.001)$ and engagement in stone processing $(\mathrm{p}=0.001)$ significantly predicted the occurrence of work-related eye injury among participants. However, age $(\mathrm{p}=0.91)$, duration of work experience $(\mathrm{p}=$ 0.19 ), and distant visual acuity status (normal vs. sub-normal, $p=0.37$ ) did not significantly predict the occurrence of work-related eye injury among participants.

Vision profile: Of the 384 participants, 373 (97.1\%) had normal visual acuity (VA) $(6 / 6$ - 6/18), 11 (2.9\%) had mild visual impairment $(<6 / 18)$ while $5(1.3 \%)$ workers had monocular blindness. The causes of monocular blindness were phthisis bulbi-1 $(0.3 \%)$, glaucoma-2 $(0.5 \%)$, anterior staphyloma-1 $(0.3 \%)$ and nystagmus $-1(0.3 \%)$. Among the workers, the causes of poor vision (VA < $6 / 18$ ) were uncorrected refractive errors-5 (1.3\%), blinding pterygium-1(1.3\%), cataracts-11 (2.9\%), corneal opacities-1 (1.3\%), glaucoma-3 (0.8\%) and maculopathies-1 (1.3\%). It is noteworthy that some participants had ocular co-morbidities resulting in poor vision. In a subgroup analysis, amongst participants with previous history of eye injury, 7 (2.5\%) had visual impairment while 2 $(0.5 \%)$ had monocular blindness.

\section{Discussion}

In our study, stone processing workers generally tended to be uneducated, married adult females, often with no or little work experience. The pro-female bias in the study is consistent with the findings in [19] but differs from the male gender dominance reported by Okoye et al. [6]. The poor work remuneration and non-requisition of pre-employment job experience make the stone industry work ideal for locally situated housewives who use the relatively meager income

Table 3. Job-specific frequencies of past eye injuries among 384 workers.

\begin{tabular}{cccccccc}
\hline \multirow{2}{*}{ Frequency } & \multicolumn{7}{c}{ Work sector } \\
\cline { 2 - 8 } & \multicolumn{7}{c}{ Stone quarry } \\
\cline { 2 - 8 } & Blaster & Driller & Breaker & Labourer & Crusher & Breaker & Labourer \\
\hline 0 & $6(40.0)$ & $20(54.1)$ & $5(33.3)$ & $34(45.9)$ & $5(71.4)$ & $5(71.4)$ & $170(74.2)$ \\
1 & $5(33.3)$ & $7(18.9)$ & $3(20)$ & $10(13.5)$ & $1(14.3)$ & $0(0.0)$ & $11(4.8)$ \\
2 & $2(13.3)$ & $1(2.7)$ & $1(6.7)$ & $3(4.1)$ & $0(0.0)$ & $0(0.0)$ & $3(1.3)$ \\
3 & $0(0.0)$ & $0(0.0)$ & $0(0.0)$ & $0(0.0)$ & $0(0.0)$ & $0(0.0)$ & $1(0.4)$ \\
$>3$ & $2(13.3)$ & $9(24.3)$ & $6(40)$ & $27(36.5)$ & $1(14.3)$ & $2(28.6)$ & $44(19.2)$ \\
Total (\%) & $15(100.0)$ & $37(100.0)$ & $15(100.0)$ & $74(100.0)$ & $7(100.0)$ & $7(100.0)$ & $229(100.0)$ \\
\hline
\end{tabular}


to supplement their husbands' income for family upkeep. This was corroborated by Uwakwe in a related survey [20].

In the present survey, the overall prevalence of work-related eye injuries was $32.0 \%$. More stone processing workers than stone quarry workers reported previous work-related eye injuries. The prevalence in the present survey is comparable to the $31.8 \%$ [21] reported in Ireland but much lower than a prevalence of $49.0 \%$ reported in Iran [22], 75.0\% among farmers in Ethiopia [8] and 52.2\% in another Nigerian report [23]. The differences may be explained by between-survey differences and similarities in participants' occupational eye health safety awareness and practices, provision and legislative enforcement of utilization of protective eye devices. Additionally, inter-industry differences in risks for eye occupational eye injury might be contributory [24]. This finding rationalizes the need for pre-employment and on-going occupational eye health education, and provision and enforced use of protective eye devices by workers in eye injury prone industrial settings.

The most prevalent ocular anterior segment disorders in the study cohort were pterygium (37.9\%), conjunctivitis (13.7\%), pingueculum (7.6\%) and cataract $(6.5 \%)$. The observed pattern of eye disorders correlates with the observations by Omoti et al. [11] where pingueculum was also a leading disorder. However, the findings differ from those of Edema et al. [9] who recorded foreign body as the commonest type of anterior segment abnormality. Between-survey similarities and differences in participant and industry characteristics, and climatic factors and influences might explain these differential observations. The high prevalence of pterygium and conjunctivitis might be attributed to the lack of environmental dust control measures or workers non-utilization of protective eye devices while at work. Additionally, the high prevalence of pterygium, a degenerative conjunctival disease, could be further attributed to the outdoor work environment and inherent exposure to ultraviolet radiation and dust. A similar dominance of degenerative ocular surface disorders have been reported by Okoye and Umeh [6], Davies and colleagues [25] Droutsas [26] Alakija [27], and Sultan [13]. Therefore, provision of preventive and therapeutic in-industry eye care interventions should receive priority for the appropriate management of these common eye disorders.

Cataracts were another common ocular anterior segment disorder in the study cohort despite the study comprising mostly young individuals. Similar to the findings of Bhurton et al. [28], this could be attributed to the cataractogenic effects of outdoor work-related chronic exposure to ultraviolet radiation and work-related ocular trauma. Although a common practice in the study area, likely abuse of topical steroids for treatment of conjunctivitis from ocular irritation was not investigated in the study. The high prevalence of cataracts among individuals aged 40 years or older in the study area might be partly contributory [29] [30]. The investigators recommend the provision of environment- and job-appropriate protective eye devices for these stone industry workers who are at augmented risk. Additionally, targeted health education of these workers in 
relation to the treatment of common ocular disorders and prevention of work-related eye injuries are instructive.

Common ocular posterior segment disorders among the study participants were glaucoma $(2.1 \%)$ and optic atrophy (1.6\%). This is in partial agreement with the findings by Omoti et al. [7] who considered petroleum industry workers in southern Nigeria. Although these might be partly accounted for by work-related exposure hazards, genetic, nutritional and immunological influences [6] are critical etiologic factors. This emphasizes the need for provision of resources for pre-employment and periodic in-service comprehensive eye examination, without resource bias for diagnosis and management of industry-related eye disorders. To this end, policy-makers and implementers of industrial health legislation should act in liaison with stone industry owners and eye care providers.

Refractive error (19.5\%) and presbyopia (4.7\%) were frequent "whole-globe" disorders noted for the study cohort. While the observed high prevalence of refractive error is attributable to this conditions being a leading cause of visual impairment in Nigeria [27] [30] the comparatively low prevalence of presbyopia could be accounted for by the comparatively younger age group of the participants aged 31 - 40 years, relative to the typical age of onset of presbyopia i.e. 35 40 years [31].

The majority (78.6\%) of the participants had normal vision; $19.8 \%$ had visual impairment and $1.3 \%$ had monocular blindness. The observed vision profile corroborates the findings by Okoye et al. [6] in a related south-eastern Nigerian study. Despite the high prevalence of eye disorders, the high proportion of workers with normal vision underscores the non-vision threatening nature of these disorders. However, this should not attenuate the vigilance of all earlier identified stakeholders in industrial eye health programs for incident visual loss among stone industry workers, through periodic screening eye examinations. This is especially important considering that normal vision has been shown to correlate negatively with occurrence of industrial accidents [28].

\section{Limitation of Study}

The conclusions drawn from this study and the extrapolations of its findings are limited by the recall bias inherent in self-reported surveys. In addition since the sample size was calculated for the stone workers as a whole, findings of prevalence in each sub strata may not be as precise as the overall estimates.

\section{Conclusion}

The prevalence of ophthalmic disorders, predominantly of the ocular anterior segment, is high among stone quarry workers in Abakiliki, Ebonyi state, Nigeria. Eye disorders resulting from work-related trauma are infrequent. Provision and enforced use of Personal Protective Eye Devises, occupational eye health education, and provision of tailored eye care services are warranted. 


\section{Authorship}

All the listed authors participated in data collection, analysis, and interpretation of data, and contributed significantly to the intellectual content of the manuscript. All authors approved the final version for submission.

\section{Acknowledgements}

My deepest appreciation goes to the workers and administrative staff of the stone quarry and stone processing plants whose cooperation made this work possible.

\section{Conflicts of Interest}

The authors report no conflict of interest, personal or institutional, in this work.

\section{Financial Disclosure}

The authors declare no external source of funding for this work.

\section{References}

[1] Definition of Quarrying by Merriam-Webster. https://www.merriam-webster.com/dictionary/quarrying

[2] Edmonds, D.J. and Nicholas, J. (2002) The State of Health and Safety in the UK Construction Industry with a Focus on Plant Operators. International Journal of Building Pathology and Adaptation, 20, 78-87.

[3] Idoro, G.I. (2008) Health and Safety Management Efforts as Correlates of Performance in the Nigerian Construction Industry. Journal of Civil Engineering and Management, 14, 277-285. https://doi.org/10.3846/1392-3730.2008.14.27

[4] Aigbedion, I.N. (2005) Environmental Pollution in the Niger-Delta, Nigeria. Inter-Disciplinary Journal, 3, 205-210.

[5] Aigbedion, I. and Iyayi, S.F. (2007) Environmental Effect of Mineral Exploitation in Nigeria. International Journal of Psychology, 2, 033-038.

[6] Okoye, O.I. and Umeh, R.E. (2000) Eye Health of Industrial Workers in Southeastern Nigeria. West African Journal of Medicine, 21, 132-137.

[7] Omoti, A.E., Waziri Erameh, M.J.M. and Enock, M.E. (2008) Ocular Disorders in a Petroleum Industry in Nigeria. Eye, 22, 925-929. https://doi.org/10.1038/sj.eye.6702772

[8] Tsfaye, A. and Bejiga, A. (2008) Ocular Injuries in a Rural Ethiopian Community. East African Medical Journal, 85, 593-596.

[9] Edema, O.T., Omoti, A.E., Akinsola, F.B. and Aigbotsua, P.A. (2009) Ocular Injuries in Industrial Technical Workers in Delta State, Nigeria. Journal of Hainan Medical College, 15, 217-222.

[10] Fiebei, B. (1993) Ocular Injuries amongst Industrial Welders in Port-Harcourt. Ophthalmology Fellowship Dissertation Presented to National Postgraduate Medical College of Nigeria.

[11] Omoti, A.E., Edema, O.T., Akinsola, F.B. and Aigbotsua, P.A. (2009) Non-Traumatic Ocular Findings in Industrial Technical Workers in Delta State, Nigeria. Middle East African Journal of Ophthalmology, 16, 25-28. 
https://doi.org/10.4103/0974-9233.48864

[12] Sultan, A.M. (2004) Health Hazards of Cement Dust. Saudi Medical Journal, 25, 1153-1159.

[13] Ayoyemi, A.A. (1987) A Study of the Health Problems and Working Conditions of Workers in the Stone Quarry Industry: Surveys in Britain and Nigeria. Fellowship Dissertation Presented to National Postgraduate Medical College of Nigeria.

[14] Workplace Eye Safety (2005) Prevent Blindness America. https://www.preventblindness.org/

[15] Occupational Safety and Health Administration (OSHA) (2011) Occupational Safety and Health Act of 1970, Section 5. United States Department of Labour. http://www.osha.gov/pls/oshaweb/owadisp.show_document?p_id=3359\&p_table= OSHACT

[16] (1990) The Laws of the Federation of Nigeria (Factories Act). Vol. 25, 5463-5493.

[17] Asogwa, S.E. (1978) Accidents in Industry. In: A Guide to Occupational Health Practice in Developing Countries, Fourth Dimension, Enugu, 87.

[18] Ezepue, U.F. and Nworah, P.B. (1990) Occupational Accidents-A Preventable Cause of Blindness and Visual Impairment in Nigeria. Orient Journal of Medicine, 2, 20-22.

[19] (2015) Association for Research and Vision in Ophthalmology 2014 Annual Meeting Proceedings. No 504: Ocular Injurie $s$ and Corneal Disease.

[20] Uwakwe, K.A. (2009) The Effect of Health Education on the Attitude and Perception towards Dust Exposure and the Use of Dust Mask among Crushers of Quarry (Crush Stone) Industry in Ebonyi State. Fellowship Dissertation Presented to the West African College of Physicians.

[21] Saeed, A., Khan, I., Dunne, O., et al. (2010) Ocular Injury Requiring Hospitalisation in the South-East of Ireland: 2001-2007. Injury, 41, 86-91.

https://doi.org/10.1016/j.injury.2009.01.118

[22] Jafari, A.K., Anvari, F., Ameri, A., et al. (2010) Epidemiology and Sociodemographic Aspects of Ocular Traumatic Injuries in Iran. International Ophthalmology, 30, 691-696. https://doi.org/10.1007/s10792-010-9401-0

[23] Mu'awiyyah, B.S. and Ogunleye, O.O. (2012) Awareness and Compliance with Use of Safety Protective Devices and Patterns of Injury among Quarry Workers in Sabon-Gari Local Government Area, Kaduna State North-Western Nigeria. Annals of Nigerian Medicine, 6, 65-70.

[24] Fiebei, B. and Awoyesuku, E.A. (2011) Ocular Injuries among Industrial Welders in Port Harcourt, Nigeria. Clinical Ophthalmology, 5, 1261-1263.

https://doi.org/10.2147/OPTH.S20297

[25] Davies, K.G., Asanga, U., Nku, C.O., et al. (2007) Effect of Chronic Exposure to Welding Light on Calabar Welders. Nigerian Journal of Physiological Sciences, 22, 55-58.

[26] Droutsas, K. and Sekundo, W. (2010) Epidemiology of Pterygium: A Review. Ophthalmologe, 107, 511-516. https://doi.org/10.1007/s00347-009-2101-3

[27] Alakija, W. (1988) Eye Problems among Cement Factory Workers in Bendel State, Nigeria. Public Health, 102, 69-72. https://doi.org/10.1016/S0033-3506(88)80012-X

[28] Burton, M., Fergusson, E., Hart, A., et al. (1997) The Prevalence of Cataract in Two Villages of Northern Pakistan with Different Levels of Ultraviolet Radiation. Eye, 11, 95-101. https://doi.org/10.1038/eye.1997.19

[29] Abdull, M.M., Sivasubramanian, S., Murthy, G.V.S., Gilbert, C., Abubakar, T., Eze- 
lum, C., et al. (2009) Causes of Blindness and Visual Impairment in Nigeria: The Nigeria National Blindness and Visual Impairment Survey. Investigative Ophthalmology \& Visual Science, 50, 9. https://doi.org/10.1167/iovs.09-3507

[30] Dineen, B., Gilbert, C.E. and Rabiu, M.M. (2008) The Nigerian National Blindness and Visual Impairment Survey: Rationale, Objectives and Detailed Methodology. BMC Ophthalmology, 8, 17. https://doi.org/10.1186/1471-2415-8-17

[31] Uche, J.N., Ezegwui, I.R., Uche, E., Onwasigwe, E.N., Uche and Onwasigwe, C.N. (2014) Prevalence of Presbyopia in a Rural Africa Community. Rural Remote Health, 14, 2731. 


\section{Appendix I}

Questionnaire on the survey of ocular problems of stone quarry and stone processing industry workers in Abakiliki, Ebonyi state, Nigeria.

Kindly fill in the blank spaces and select appropriate option where it applies. All responses are kept confidential.
2. Name
3. Age:
a. $10-20$
b. $20-30$
c. $30-40$
d. $40-50$
e. 50 - 60
f. $>60$
4. Sex:

A. Personal data

1. Serial number

Male/Female

5. Marital status

a. Single

b. Married

c. Widowed

d. Separated

e. Divorced.

6. State of origin

7. Educational background-circle as appropriate
a. None
b. Primary school
c. Secondary school
d. Post sec school
e. Others
8. Hand dominance?

Right/Left

\section{B. Industrial work history}

9. Place of work?

Quarries/Processing plant/Others specify

10. Nature of work?

Blaster/Driller/Crusher/Breaker/Labourer

11. Duration of service (years):
a. $<1$ year
b. 1 - 5
c. 5 - 10
d. 10 - 15
e. 15 - 20 
f. $>20$

12. Hours per day at work
a. 1 - $6 \mathrm{hrs}$
b. 7 - $12 \mathrm{hrs}$
c. $13-18$ hrs

13. How many work related accidents have you been involved in?

a. None

b.1

c. 2

d. 3

e. Many times

14. How many times were the eyes involved?
a. None
b. 1
c. 2
d. 3
e. Many times.

Which eye?

Left Eye/Right Eye/Both Eyes.

15. Type of injury

a. Blunt

b. Penetrating

c. Foreign body

d. Abrasion

e. Burns

16. Part of body affected

17. Agent of injury

18. Predisposing factor:
a. Hunger
b. Work exhaustion
c. Tension at home
d. Acute systemic
e. Illness
f. Proximity to machine
g. Overconfidence
h. Environmental exposure
19. Time of occurrence:
a. Morning
b. Mid morning
c. Afternoon
d. Mid afternoon
e. Evening

20. What treatment did you receive?

Medical/Surgical/traditional/spiritual/None 
21. Where did you receive the treatment after the accident? Public hospital/Private hospital/Native doctor/Chemist/None

22. How long were you absent from work?

0 - 2 days/>2 days - 1 month/>1 month - years

23. Do you wear any eye protection during work?

Yes/No

24. If yes, what type?

Plastic goggles/Glass goggles/Polycarbonate goggles

25. If No, why not?

a. Don't believe it works

b. Unavailable

c. Costly

d. Uncomfortable with it

e. Can't see with it

f. Others specify.

26. Did you undergo any pre employment eye test?

Yes/No

27. If yes,

Official/Private

28. Do you know about eye protective devices?

Yes/No

29. Are they available?

Yes/No

30. Do you use eye protective devices?

Yes/No

31. If yes, why?

a. To protect eyes from injury

b. To protect eyes from eye diseases from work

c. To protect against sun

d. Mandated by employer to use them

e. Others specify

32. If No, why?

a. Can't see with them

b. Gives eye discomfort

c. Not used to them

d. Not allowed by employer to use them

e. Too costly

f. Not available

C. Ocular history/examination

33. Did you have any eye problems before you gained employment at the quarry?

Yes/No

34. If yes, what were they? 
35. How long?

$>1$ year/ 1 - 5 years/ $>6-10$ years/ $>10$ years

36. Has it worsened or improved?

Yes/No

37. Do you have any eye complaints presently?

Yes/No

38. If yes, what are your complaints?

39. Which eye?

RE/LE/Both

40. Duration?

$<1$ year/ 1 - 5 years/ $>5-10$ years/ $>10$ years

41. Any current treatment?

Medical/Surgical/Chemist/Traditional/Spiritual/None

42. Do you think your type of work contributed to it?

$\mathrm{Yes} / \mathrm{No}$

43. Do you have health talks on ways of preventing injury at your place of work?

Yes/No

\section{Appendix II. Examination}

Right eye

Left eye

Visual acuity (far)

With glasses

With pinhole

Binocular vision

Nearvision (unaided)

(Aided)

Lids

Ocular motility

Globe

Lacrimal apparatus

Conjunctiva

Cornea

Anterior chamber

Iris

Pupil

Lens

Fundus

Normal

Abnormal

Visual fields: Right eye 